\title{
The Value of Hystersocopy; Ultrasonogrphy and Histopathology in Diagnosis of Chronic Endometritis in Patients with Unexplained Recurrent Spontaneous Abortion
}

\author{
IBRAHEEM M. KANDIL, M.D.*; ASEM A. MOUSA, M.D.*; MOHAMED A. MOHAMED, M.D.*; \\ SAYED A. SAYED, M.D.** and RASHA S. GHORAB, M.Sc.* \\ The Departments of Obstetrics and Gynecology* and Histopathology**, Faculty of Medicine, Al-Azhar University
}

\begin{abstract}
Background: Recurrent Spontaneous Abortion (RSA) defined as the loss of three or more consecutive pregnancies before the 20 weeks of gestation or a fetal weight of less than 500 grams.

Aim of Study: To investigate the role of Chronic Endometritis (CE) in unexplained RSA and to determine the correlation between hysteroscopic, Doppler ultrasonography and histologic findings of $\mathrm{CE}$ in patients with unexplained RSA.

Patients and Methods: This prospective controlled study was conducted in Al-Hussein University Hospital, Al-Azhar University. Forty consecutive patients with unexplained RSA referring to the infertility clinic (from May 2016 till January 2019) were enrolled in this study to investigate the role of CE in RSA. A control group of other twenty fertile women who underwent hysteroscopy due to vaginal bleeding or causes other than RSA and infertility were also included.
\end{abstract}

Results: Suggested that the measurement of previous hormone levels, blood flow by color Doppler can discriminate endometritis from potentially normal women. The data in our study also suggested that there were significant differences as regards luteal phase disorders.

Conclusion: Chronic endometritis was not incriminated as a cause for repeated first trimestric abortion in patients with repeated unexplained spontaneous abortion

Key Words: Recurrent spontaneous abortion - First trimesteric - Endometritis - Luteal phase defects - Subintimal blood flow-Doppler-Hysteroscopy.

\section{Introduction}

RECURRENT Spontaneous Abortion (RSA) defined as the loss of three or more consecutive pregnancies before the 20 weeks of gestation or a fetal weight of less than 500 grams, is one the most common complications of pregnancy, occurring in

Correspondence to: Dr. Rasha S. Ghorab,

E-Mail: <nrsdoc_84@yahoo.com about $1 \%$ of couples [1]. Common causes of RSA are genetic abnormalities [2], congenital or acquired uterine malformation, endocrine dysfunction. thrombophilic disorders, autoimmune diseases, incompetent cervix, luteal phase defect, certain infections, and Sperm DNA abnormalities. Even after a thorough evaluation, however, the potential cause remains unexplained in about one third to one half of the cases [3] . Chronic Endometritis (CE) is a persistent inflammation of endometrium and is often asymptomatic or accompanied by mild symptoms including pelvic pain, dysfunctional uterine bleeding, dyspareunia and leucorrhea [4]

It is also associated with decreased pregnancy rates. In Vitro Fertilization (IVF) as well as poor obstetric outcomes like preterm labor and preterm birth [5]. Several studies showed that CE plays an important role in repeated implantation failure [6], although some concluded otherwise [7].

Hysteroscopy is the only access route for direct visualization of the uterine cavity. It has been suggested that hysteroscopy without endometrial biopsy has a low positive predictive value in the detection of intrauterine inflammatory status [8].

Hysteroscopy with endometrial biopsy is assumed to be the best method for the detection of intrauterine abnormalities. Histologically, the diagnosis of CE is generally based on finding a plasma cell infiltrate in an endometrial biopsy. On the other hand, diagnosis of CE on hysteroscopy depends on the presence of Stromal edema, focal or diffuse hyperemia and in some cases, endometrial micropolyps (less than one millimeter in size). Unfortunately, data and evidence regarding the role of CE in RSA are Scarce. To the best of our knowledge, the correlation between CE and RSA 
has not been proven. Thus, we performed this study to investigate the role of CE in unexplained RSA and to determine the correlation between hysteroscopic, Doppler ultrasonography and histologic findings of CE in patients with unexplained RSA.

\section{Patients and Methods}

This prospective controlled study was conducted in Al-Hussein University Hospital, Al-Azhar University. Forty consecutive patients with unexplained RSA referring to the infertility clinic were enrolled in this study to investigate the role of CE in RSA. A control group of other forty fertile women who underwent hysteroscopy due to vaginal bleeding or causes other than RSA and infertility were also included.

The study protocol was approved by the Local Ethical Committee of Faculty of Medicine, AlAzhar University. An informed written consent was taken from all patients and their husbands before starting the study and every patient had the right to leave the study at any time.

All participants were subjected to the following: Hysteroscopic evaluation to evaluate the mucosa and ultrasonography and doppler of the uterine subendothelial blood vessels. CE was suspected when hysteroscopy revealed signs of focal or diffuse endometrial hyperemia. The pathology of the endometrium was considered as the gold standard for the diagnosis of endometrial abnormalities. The sensitivity, specificity, positive predictive value, and negative predictive value of hysteroscopy were calculated on the basis of pathologic reports. The histopathologic diagnosis after endometrial Sampling and biopsy of CE was based on superficial stromal edema, increased stromal density, and pleomorphic stromal inflammatory infiltrate dominated by lymphocytes and plasma cells. In other words, CE was defined as the presence of plasma cells in the endometrial stroma and considered the biopsies negative for $\mathrm{CE}$ if less than one plasma cell per high-power field was seen.

A- Careful history taking, including symptoms of androgen excess such as acne or hirsutism, menstrual irregularities, and medications for induction of ovulation.

B- Thorough clinical examination, including height, body weight and BMI.

C- Hormonal profile was done for all subjects.

\section{Inclusion criteria:}

Patients with primary 3 spontaneous abortions at first trimester, aged 20-35 years, with Body Mass Index (BMI) $20-30 \mathrm{~kg} / \mathrm{m}^{2}$.

\section{Exclusion criteria:}

Age $<20$ or $>35$ years or BMI $<20$ and $>30$ $\mathrm{Kg} / \mathrm{m}$. Patients with recurrent abortion such as hormonal disorders, infections, genetic anomalies, immunologic problems, thyroid dysfunction were also excluded,positive lupus anticoagulant and anticardiolipin antibodies, abnormal serum testosterone level. Luteal Phase Defect (LPD) was not ruled out, history of preeclampsia or intrauterine growth retardation. Smoking and history of alcohol consumption.

\section{Statistical analysis:}

Data were statically represented in terms of range, mean. Standard deviation and percentages. Comparison between different group in the present study was done using student $t$-test for comparing parametric data, for comparing non-parametric data chi square $(\chi)$ test was performed. Correlation between various variables were done using Person correlation coefficient $(r)$ with graphic representation using linear regression line, a probability value ( $p$-value) less than 0.05 was considered significant, accuracy was represented using the terms sensitivity. specificity, positive and negative predictive values and overall accuracy.

All statistical calculations were done using computer programs Microsoft Excel Version 2007 and SPSS program.

\section{Results}

Table (1): Clinical data of the control \& abortion groups.

\begin{tabular}{lll}
\hline Parameter & $\begin{array}{c}\text { Control } \\
\text { group } \\
\mathrm{N}=40\end{array}$ & $\begin{array}{c}\text { Abortion } \\
\text { group } \\
\mathrm{N}=40\end{array}$ \\
\hline Mean age (years) $\pm \mathrm{SD}$ & $27.3 \pm 4$ & $26.75 \pm 4.77$ \\
Mean parity SD & $2.6 \pm 1.05$ & $1.00 \pm 1.36$ \\
Mean gravidity $\pm \mathrm{SD}$ & $2.6 \pm 1.05$ & $4.3 \pm 2.44$ \\
Mean number of abortion $\pm \mathrm{SD}$ & 0 & $3.3 \pm 1.7$ \\
\hline
\end{tabular}

Table (2): Clinical data of Luteal Phase Defect (LPD) vs. nonLPD cases.

\begin{tabular}{lll}
\hline Parameter & $\begin{array}{c}\text { Subgroup IIA } \\
\text { (LPD) } \\
\mathrm{N}=14\end{array}$ & $\begin{array}{c}\text { Subgroup IIB } \\
\text { (Non-LPD) } \\
\mathrm{N}=26\end{array}$ \\
\hline Mean age (years) $\pm \mathrm{SD}$ & $25.86 \pm 5.86$ & $27.23 \pm 4.12$ \\
Mean parity $\pm \mathrm{SD}$ & $0.29 \pm 0.47$ & $1.38 \pm 0.53$ \\
Mean gravidity $\pm \mathrm{SD}$ & $2.86 \pm 0.86$ & $5.08 \pm 2.67$ \\
Mean no. of abortions $\pm \mathrm{SD}$ & $2.57 \pm 0.76$ & $3.69 \pm 1.93$ \\
\hline
\end{tabular}


Table (3): Comparison between LPD \& non-LPD cases as regard the type of abortion.

\begin{tabular}{llc}
\hline & $\begin{array}{c}\text { Subgroup IIA } \\
\text { (LPD) }\end{array}$ & $\begin{array}{c}\text { Subgroup IIB } \\
\text { (Non-LPD) }\end{array}$ \\
\hline Primary aborters & $10(71.4 \%)$ & $14(53.8 \%)$ \\
Secondary aborters & $4(28.6)$ & $12(46.2 \%)$ \\
$\chi^{2}$ & 0.554 & \\
$p$ & $>0.05 *$ & \\
\hline
\end{tabular}

*: Primary aborter: Patients who have never carried a fetus to viability.

*: Secondary aborter: Patients who have a history of at least one viable delivery before the series of spontaneous losses.

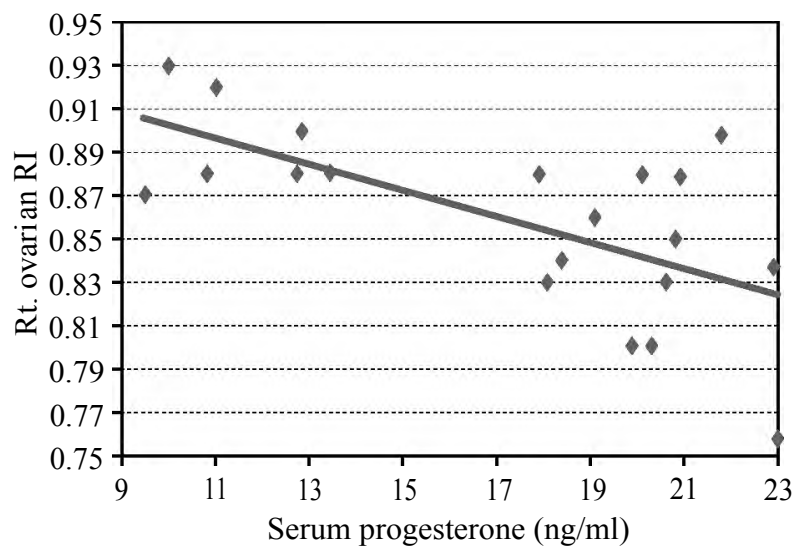

Fig. (1): Mean serum progesterone level among the abortion.

\section{Discussion}

Despite the convincing evidence of continued improvement in both maternal and fetal outcome, recurrent abortion remains a distressing problem for both the gravid woman as well as her obstetrician. In natural menstrual cycles, the uterine endometrium shows structural and functional changes that can be followed macroscopically and noninvasively by vaginal ultrasonography [9]. The most typical ultrasound findings are of multilayered endometrium in the follicular phase which is homogenous and hyper echogenic in the midluteal phase. However, other patterns have already been detected from the follicular phase [10]. Proposed that the cause for repeated abortions due to scanty endometrium is defective vascularization of the latter on the basis of occlusion damage of the arterial vessels of the uterus. The investigation of the uterine cavity is of paramount importance in the work up of habitual aborters. Hysteroscopy has become an essential technique in the current practice of gynecology. It allows visualization of the uterine cavity properly and detect any intrauterine pathology. In present work, the studied cases were classified into two groups: Group I (control group) which included 40 normal fertile females with no history of abortion, a mean age of $27.3 \pm 4$ years and a mean parity of $2.6 \pm 1.05$. They were subjected to transvaginal color Doppler evaluation of the uterine arties, Group II (recurrent abortion group) included 40 patients with at least two consecutive first trimesteric pregnancy losses with mean age of $26.75 \pm 4.77$ years, mean parity of 1.00 \pm 1.36 and mean number of abortions was $3.3 \pm 1.7$. They were subjected to transvaginal color Doppler evaluation together with diagnostic hysteroscopy, dated endometrial biopsy and detection of midluteal serum progesterone levels. The abortion group was further subdivided according to the histopathology into LPD and non-LPD subgroups. The LPD subgroup (14 cases) had a mean age of $25.86 \pm 5.86$ (range $33-18$ years), mean parity of $0.29 \pm 0.47$ (range of 1-0), mean number of previous losses was $2.57 \pm 0.76$ per patient (range of 2-4). The diagnosis of LPD was fortified by finding low progesterone concentrations in the mid-luteal phase of these patients. The non-LPD subgroup (26 cases) had a mean age of $27.23 \pm 4.12$ (range 3522 years), mean parity of $1.38 \pm 0.53$ and the mean number of previous losses was $3.69 \pm 1.93$ (range of 2-9). There were no previous live births for 14 patients $(53.8 \%)$.

In the present study, LPD was found in 14 of $40(35 \%)$ patients.

Endometrial thickness transvaginal ultrasound was performed to all patients for monitoring of endometrial development. The mean endometrial thickness in the abortion Group (II) during the mid-follicular phase was $7.60 \pm 1.91$ vs. $8.01 \pm 2.03$ in the control Group (I), $p>0.05$. The same occurred in the mid-luteal phase, where the mean endometrial thickness in Group II was lower than that of Group I but with no statistical significance as shown. Our findings were consistent with those of [11], who considered the endometrial thickness as an inappropriate criterion for diagnosing LPD and found no statistical differences between the normal and the luteal phase defect group.

Vascular Doppler changes in cases of recurrent abortion during the normal menstrual cycle, a sharp increase is observed in the end-diastolic velocities between the proliferative and the secretory phases [12] . It is particularly interesting that the lowest blood flow impedance occurs during the time of peak luteal function, during, which implantation is most like to occur [13]. In the present work, the uterine RI was detected and analyzed in all the examined cases $(\mathrm{N}=80)$. The uterine $\mathrm{RI}$ in the abortion group was significantly higher than the control group during the mid-follicular and midluteal phase of the cycle, $p<0.05$ this study clearly demonstrated that patients with a delayed endome- 
trial pattern (LPD) are characterized by increased uterine vascular resistance during the luteal phase (0.90) when compared to the normal groups as shown. On the contrary, patients with normal endometrial development showed regression of the uterine impedance from the follicular to the luteal phase in both the control and the non-LPD groups (the mean RI was 0.87 during the follicular phase for both groups and decreased to $0.83,0.84$ in the mid-luteal phase for both the control and non-LPD patients, respectively). These results can be explained by the fact that the decrease in RI in normal subjects is primarily the result of an increase in end diastolic flow. In LPD cycles, there is no progressive increase in end diastolic flow and consequently the RI remains higher.

Progesterone appears to have a critical role in the implantation and continuation of a normal pregnancy. Marked decrease in progesterone secretion may result in infertility while in milder forms recurrent pregnancy loss may occur. In the present study, the mid-luteal serum progesterone was estimated in Group II (abortion group). The mean progesterone "levels were significantly lower in subgroup IIA (LPD patients) than in subgroup IIB (non-LPD patients) $(11.46 \pm 1.45 \mathrm{ng} / \mathrm{ml}$ vs. $20.21 \pm$ $1.65 \mathrm{ng} / \mathrm{ml}, p<0.000)$ as shown.

Hysteroscopic evaluation of the endometrium: Hysteroscopic inspection of the uterine cavity offers simple method to investigate uterine, endometrial and endocervical pathology. It allows a thorough inspection of the uterine cavity facilitating an accurate diagnosis and therapeutic intervention whenever indicated. Hysteroscopic examination of the abortion group revealed a normal uterine cavity in 26 patients $(65 \%)$. Intrauterine changes was diagnosed in 14 patients (35\%) among whom 6 patients $(15 \%)$ had uterine anomalies (subseptate in four patients/Bicornuate in two patients) that required diagnostic laparoscopy to confirm the diagnosis, four patients (10\%) had mild intrauterine adhesions and four patients (10\%) had submucous myomas [13], considered the finding of 3 criteria on hysteroscopic examination to be termed a "negative hysteroscopic view ". These criteria are: Good visualization of the uterine cavity, no structural abnormalities in the uterine cavity, a uniformly thin homogenous appearing endometrium without variation in thickness. Poor vascularization of the septum may be implicated as the reason for defective implantation suggested that such vascularization is even poorer in cases of a partial septum, and therefore the chance for success is less in such gestations.
Finally, there is great difficulty in determining whether there is, in fact, a subgroup of recurrent abortion women whose endometrial development is so deficient that normal implantation cannot be continued successfully. The present study suggests that color Doppler assessment of the endometrium may be able to predict endometrial receptivity. Hysteroscopy following abortion seems to be an easy and cost-effective means of identifying intrauterine pathology that may be the cause of recurrent abortion in patients who desire a further pregnancy.

\section{Conclusion:}

Spontaneous abortion is the most common complication of pregnancy and is responsible for significant emotional distress to couples desiring children. Approximately, $70 \%$ of human conceptions fail to achieve viability, and the true early pregnancy loss rate is closer to $50 \%$ because of the high rate of unrecognized pregnancy losses in the 2-4 weeks immediately following conception. The present study revealed that LPD represents a very important etiology for-recurrent first trimesteric abortion. It was found in 14/40 (35\%) of cases with recurrent first trimesteric abortion as diagnosed by endometrial histopathology and mid luteal serum progesterone. It also was proved that chorinc endometritis isn't incriminated in spontaneous pregnancy loss.

\section{References}

1- ROBERTS C.P. and MURPHY A.A.: Endocrinopelthies associated with recurrent pregnancy loss. Semin Reprod Med., 18: 357-62, 2002.

2- FEDELE L. and BIANCHI S.: Habitual abortion. Endocrinological aspect. Curr. Opin. Obstet. Gynecol., 7: 3516, 2005.

3- KLINE J., SLTFOUT P., STEIN Z., SUSSER M. and WARBURTON D.: Recurrent early pregnancy loss and consanguinity. Rep. Biomed. Online, 167-70, 2011.

4- CRANE J.P. and WAHL N.: The role of maternal diabetes in repetitive spontaneous abortion. FertillSteril, 36: 477 9, 2009.

5- COULAM C.B. and STERN J.J.: Endocrine factors associated with recurrent spontaneous abortion. Clin. ObstetGynecol., 37: 730-4, 2009.

6- CARRINGTON B., SACKS G. and REGANT L.: Recurrent miscarriage pathophysiology and outcome. Curr. Opin. Obstet. Gynecol., 17: 591-7, 2015.

7- KAZEROONI T., ASADI N., JADID L., et al.: Evaluation of sperm's chromatin quality with Acridine Orange test, chronomycinA3 and aniline blue Staining in couples with unexplained recurrent abortion. J. Assist. Reprod Genet., 26: 591-6, 2009.

8- Scientific advisory committee of the Royal College of Obstetrioian sand Gynaecologists: The management of 
recurrent miscarriage. RCOG 'Green-top' Guideline No. 17, 2001.

9- KLINE J., SLTFOUT P., STEIN Z., SUSSER M. and WARBURTON D.: Luteal phase defect: Comparsion between Doppler velocimetry, histological and hormonal markers. Ultrasound Obstet. Gynecol., 9: 105-12, 2011.

10-POLISHUK W.Z., SIEW F.P., GORDON R., et al.: Vascular changes in traumatic amenorrhoea and hypomenorrhoea. Int. J. Fert., 22: 189, 2011.

11- STERZIK K., ABT M., GRAB D., SCHNEIDER V. and STREHLER K.: Predicting the histologic dating of an endometrial biopsy specimen with the use of Doppler ultrasonography and hormone measurments in patients undergoing spontaneous ovulatory cycles. Fertil \& Steril, 73 (1): 94-8, 2000.

12- KUPESIC S., KURJAK A., VUJISIC S. and PETROVIC Z.: Luteal phase defect: Comparsion between Doppler velocimetry, histological and hormonal markers. Ultrasound Obstet. Gynecol., 9: 105-12, 2014.

13- LOFFER F.D.: Hysteroscopy with selective endometrial sampling compared with $\mathrm{D}$ and $\mathrm{C}$ for abnormal uterine bleeding: The value of a negative hysteroscopic view. Obstet. Gynecol., 73: 16, 2009.

\title{
قيمة منظار الرحم، السونار وتحليل العينات

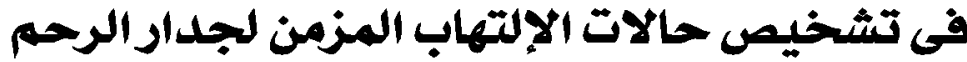

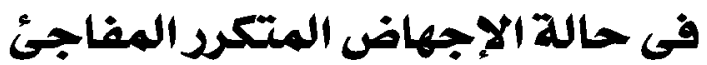

\author{
يعتبر الإجهاض المتكرد فى الآشهر الآولى من الحمل من الآشياء الشائعة التى تعدد آسبابها ولما يحصى جميع آسبابها. \\ من ضمن الآسباب الإلتهاب المزمن بجدار الرحم المتمثة أعراضه فى الآلام المزمنة بالحوض والنزيف الرحمى، كما يسبب ضعف نسب

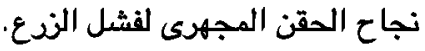

يعتبر المنظار الرحمى من آهم وسائل التشخيص حيث آنه يتيع الرؤية المباشرة لما يحتويه الرحم من مشاكل إحتمالية تواجد عيوب خلقية

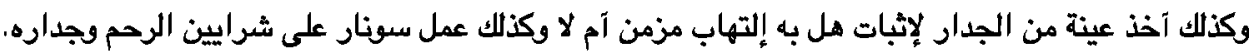

وقد ثبت من واقع دراستتا المتآنيه آن الإلتهاب المزمن حسب دراستنا ليس من الآسباب الشائعة وآن تشخيصها يكون بإستبعاد الآسباب الآخرى مما يقتضى المزيد من التقصى للوصول إلى جميع الآسباب المحتملة. 